Rakenteiden Mekaniikka (Journal of Structural Mechanics)

Vol. 50, No 3, 2017, pp. $283-286$

https://rakenteidenmekaniikka.journal.fi/index

https://doi.org/10.23998/rm.64922

(c) The author(s) 2017.

Open access under CC BY-SA 4.0 license.

\title{
Elastohydrodynamic simulation of the slider bearing
}

\author{
Liang Bai ${ }^{1}$, Teemu Kuivaniemi, Pasi Halla-aho and Tero Frondelius
}

Summary. This article describes the elastohydrodynamic simulation of the slider bearing in a bearing test rig and investigates the root cause for the phenomena observed from the rig test.

Key words: elastohydrodynamic, slider bearing, Wärtsilä

Received 15 June 2017. Accepted 14 August 201\%. Published online 21 August 2017

\section{Introduction}

The elastohydrodynamic (EHD) analysis method has been a powerful tool for studying oil film lubrication performance in the engine slider bearings as long as the oil film remains within the scope of full film lubrication regime. The market competition has led to the demand for higher load, higher reliability and lower loss on engine bearings. In some occasions, bearings partially operate in mixed lubrication regime. In order to develop the know-how in mixed lubrication, both a bearing test rig and a simulation model have been developed.

During the rig test, it is desired to create such load conditions that could form evenly distributed hydrodynamic pressure and gradually reduce the oil film thickness until varying degrees of bearing failures are achieved. In contrast, the test results show a highly inclined bearing load, an uneven wear pattern at the bearing edge but not the desired bearing failures under the evenly distributed high load.

A multi-body system simulation model, incorporating EHD bearings, is built to simulate the rig structure dynamics and the bearing lubrication. The root cause for not achieving the desired bearing failure is investigated on the basis of the EHD simulation results.

\section{Methods}

The hydrodynamic behavior of the oil film in the slider bearing is governed by the ordinary isothermal form of Reynolds equation.

\footnotetext{
${ }^{1}$ Corresponding author. liang.bai@wartsila.com
} 
The deformation of the bearing surface and the global vibrational motion of the rig structure are determined by solving the equations of motion $[7,4]$ for the condensed finite element model of the complete structure.

\section{Modeling}

The bearing test rig consists of a balancing shaft which generates centrifugal force by rotating an eccentric mass. At both ends of the shaft, slider bearings are installed in the cylinder-shaped bearing housings, the flange of which is bolted onto the wall of the rig structure.

It is suspected that both the bearing housing's local deformation and the rig structure's global deformation have contributed to the bearing's hydrodynamic performance. Therefore the multi-body dynamic model has to include the complete rig structure which is discretized by the finite element method with $426 \times 10^{3}$ degrees of freedom and the material properties of which are all isotropic linear elastic. The full finite element model is condensed to a super element, intended for multi-body dynamic simulation, with $9.2 \times 10^{3}$ degrees of freedom. To isolate the impact of the global rig structure deformation, two different elasticities have been assigned to it, namely steel for the flexible structure and infinite Young's modulus for the rigid structure.

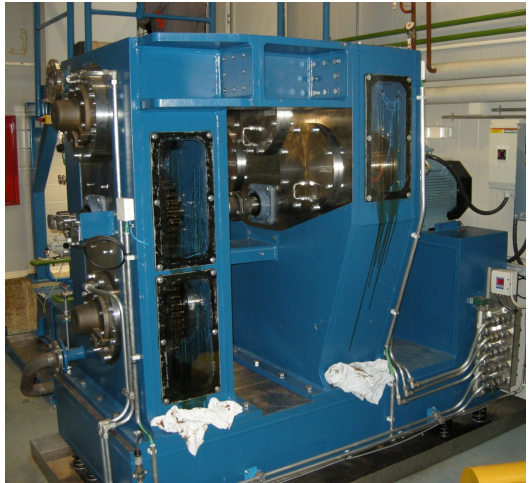

(a)

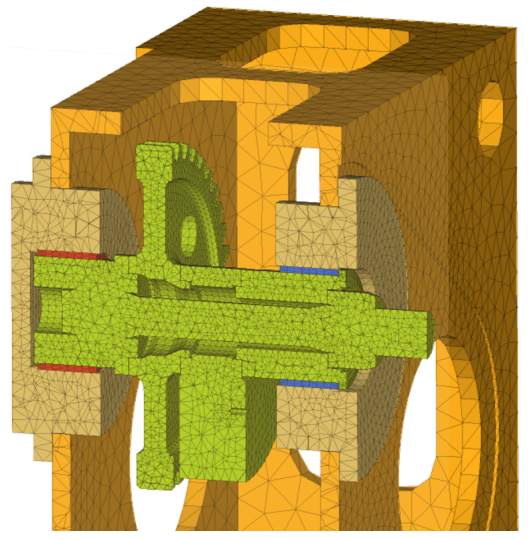

(b)

Figure 1. (a) bearing test rig (b) FEM model of the test rig

To increase the mean specific load of the bearing but maintain the sliding speed, it is decided to reduce the bearing width in steps by machining the end surface.

In solving the Reynolds equation, a constant dynamic viscosity at the ambient pressure and an estimated bearing operating temperature is applied to the oil. It is known that increasing the bearing load would result in an increase in both the hydrodynamic pressure and the oil temperature, which will have counter-effect on the oil viscosity. Simultaneously modeling the oil viscosity's dependencies on both the pressure and the temperature would increase the complexity of the analysis. Therefore it's not considered at this stage of the project.

AVL EXCITE has been used to simulate the rig structure's dynamic behavior and the bearing's EHD performance thanks to its capability of fully coupling hydrodynamics with multi-body system dynamics $[1,2,3,5,6]$. 


\section{Results and conclusions}

Figure 2 compares the rig structure deformation and bearing oil film thickness between the flexible structure and the rigid structure. For the flexible structure, the end wall of the rig wobbles and its global deformation is significantly larger than the local bearing housing deformation, which changes the bearing load pattern. For the flexible structure, minimum oil film thickness occurs at the outer edge. In contrast, for the rigid one, it occurs at the opposite edge.

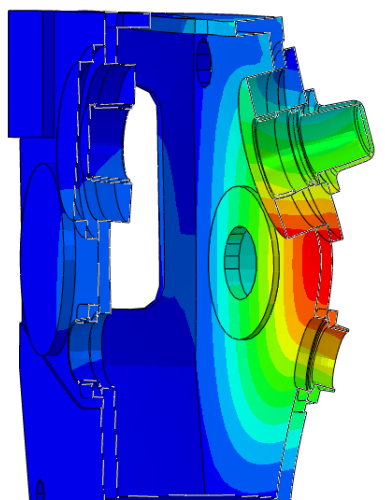

(a)

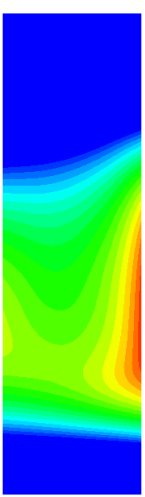

(b)

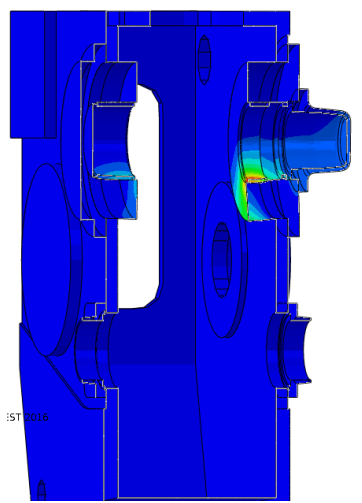

(c)

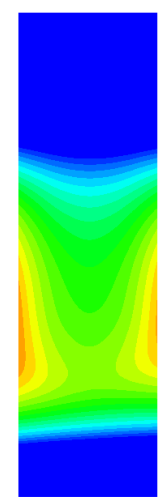

(d)

Figure 2. (a) and (b) deformation and oil film of flexible structure (c) and (d) deformation and oil film of rigid structure

Figure 3 shows the trend of the minimum oil film thickness and the maximum hydrodynamic pressure when reducing the bearing width from $60 \mathrm{~mm}$ to $30 \mathrm{~mm}$ in a $10 \mathrm{~mm}$ increment. The contour plots show the oil film thickness distribution under various bearing widths. When the mean bearing specific load is increased by the means of reducing the bearing width, the minimum oil film thickness is decreased accordingly. However, the small oil film thickness is only found at the outer bearing edge within a very narrow area, which is not sufficient to achieve the desired bearing failure.

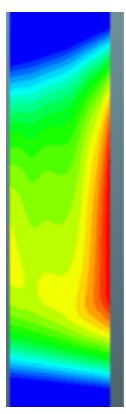

(a)

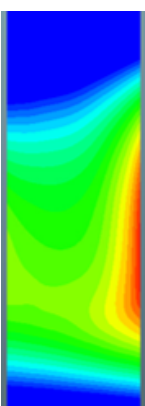

(b)

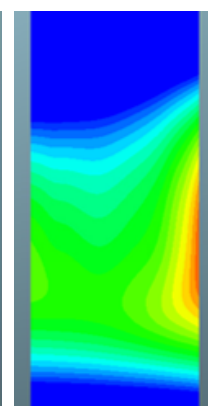

(c)

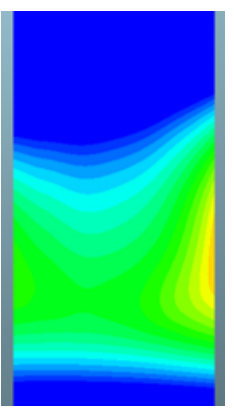

(d)

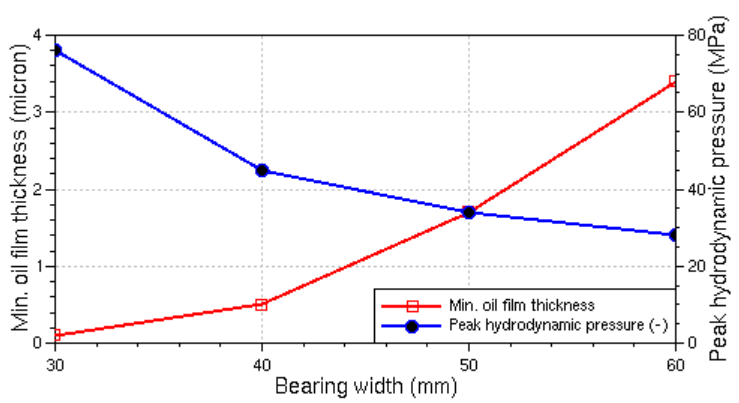

(e)

Figure 3. (a) to (d) oil film of $30 \mathrm{~mm}$ to $60 \mathrm{~mm}$ wide bearings, (e) minimum oil film thickness and peak hydrodynamic pressure

The multi-body system simulation coupled with EHD bearings reveals the root cause for not achieving the desired bearing failures on the test rig. The global structure wobbling gives significantly larger deformation than the local bearing housing deformation and changes the load pattern. Bearings are unevenly loaded so that low oil film thickness is 
only found in a limited bearing surface area, which is not the desired load condition for achieving the bearing failure.

\section{References}

[1] Tero Frondelius, Pasi Halla-aho, and Antti Mäntylä. Crankshaft development with virtual engine modelling. In CIMAC Congress Helsinki, 2016.

[2] Jussi Göös, Anton Leppänen, Antti Mäntylä, and Tero Frondelius. Large bore connecting rod simulations. Rakenteiden Mekaniikka, 50(3):275-278, 2017. URL https://doi.org/10.23998/rm.64658.

[3] Teemu Kuivaniemi, Antti Mäntylä, Ilkka Väisänen, Antti Korpela, and Tero Frondelius. Dynamic gear wheel simulations using multi body dynamics. Rakenteiden Mekaniikka, 50(3):287-291, 2017. URL https://doi.org/10.23998/rm.64944.

[4] Ming-Tang Ma and Bernhard Loibnegger. Simulation of ehd lubrication of commonpin conrod big end bearings in high speed ic engines. In World Tribology Congress III, pages 547-548. American Society of Mechanical Engineers, 2005.

[5] Antti Mäntylä, Jussi Göös, Anton Leppänen, and Tero Frondelius. Large bore engine connecting rod fretting analysis. Rakenteiden Mekaniikka, 50(3):239-243, 2017. URL https://doi.org/10.23998/rm.64914.

[6] Ilkka Väisänen, Antti Mäntylä, Antti Korpela, Teemu Kuivaniemi, and Tero Frondelius. Medium speed engine crankshaft analysis. Rakenteiden Mekaniikka, 50(3): 341-344, 2017. URL https://doi.org/10.23998/rm.64916.

[7] AVL Workspace. Excite-power-unit theory. AVL User Manuals, 2007.

Liang Bai, Teemu Kuivaniemi, Pasi Halla-aho and Tero Frondelius

Wärtsilä

Järvikatu 2-4

65100 Vaasa

liang.bai@wartsila.com, teemu.kuivaniemi@wartsila.com, pasi.halla-aho@wartsila.com, tero.frondelius@wartsila.com 